\title{
Opportunities of Geometric Documentation of Historic Buildings with Terrestrial Laser Scanner, Examples from Aksaray/Turkey
}

\section{S. Armağan GÜLEÇ KORUMAZ* Grazia TUCCI ${ }^{\star *}$ Mustafa KORUMAZ ${ }^{\star \star *}$ Valentina BONARA ${ }^{\star \star \star \star}$}

\section{Abstract}

Detailed and accurate measurements can be done by using laser scanning technology compared to conventional methods in documentation of cultural heritage. Accuracy of measured data directly affects the protection of historical buildings and decision-making process. By processing laser scanning data, multipurpose $3 \mathrm{~d}$ models can be obtained and all work and results can be shared via internet. Moreover, a detailed analysis of the building can be made with this data and it can be transferred to all related engineering and archeological fields. Despite the advantages of this technology, it has not been used widely yet in production of architectural projects. High cost of equipment and data processing software have been seen as main obstacles for widespread using of this technology. As well as, lack of integration of this topic into architectural education and less number of researcher studying in this field restrict the use of laser scanner. In this paper, evaluations were made in order to define the possibilities by using laser scanner technologies in process of restoration projects of which number is getting increased in last decades in Turkey. Positive and negative aspects of technology observed in survey process were given
Keywords: Geometric documentation, terrestrial laser scanner (TLS), architectural preservation, restoration project

${ }^{*} P h D$. Faculty of Art and Design, Department of Architecture, Konya, TURKEY E-mail: gulec.armagan@gmail.com ORCID ID: http://orcid.org/0000-00032547-3085

**Assoc. Prof. Dr. GeCO Lab, Department of Civil and Environmental Engineering, University of Florence, ITALY. grazia.tucci@unifi.it ORCID ID: http://orcid.org/0000-00017657-9723

***PhD, Faculty of Art and Design, Department of Architecture, Konya, TURKEY E-mail: mkorumaz@gmail.com ORCID ID: http://orcid.org/0000-00016337-9087

****PhD. GeCO Lab, Department of Civil and Environmental Engineering, University of Florence ITALY.

E-mail: valentina.bonora@archimetro.it ORCID ID: http://orcid.org/0000-00034489-7932 
with a case study, a small traditional house in province of Aksaray and surroundings.

\section{INTRODUCTION}

The importance of cultural heritage documentation has been recognized by the time and today there is an increasing demand for documentation of cultural heritage. This demand has prompted international organizations for creating a guideline to describe the standards for documentation. They underline the importance of cultural heritage documentation for the purposes of identification, conservation, management, assessment, interpretation, archiving, publication and research. Important ones include the International Council on Monuments and Sites, ICOMOS (2005) and UNESCO, including the Venice Charter, The International Charter for the Conservation and Restoration of Monuments and Sites, 1964 (Amans et. al., 2013; Yilmaz et. al., 2007; Parias, 2009).

Even the international organizations, charters and declarations emphasize the importance of documentation, not all of them specifically defines the geometric documentation. Despite the attention of these organizations, there are still cultural sites without sufficient documentation. According to LeBlanc et al., 2005 , only a third of the eight hundred sites on the World Heritage List are adequately documented in terms of geometric documentation (Amans et. al., 2013).

Through the remarkable technological advances in last years, the collection of the metric data for geometric documentation of a monument is facilitated. So several techniques are being used for geometric data acquisition today. Among these techniques terrestrial laser scanning has become very popular considering its advantages. Since its results also can be combined with photogrammetry, it produces metric documents and data for monuments which is a good contribution for monitoring, conservation and documentation of the monuments.

This paper suggest a way of documentation by using 3D laser scanning technology and describes the steps carried out for geometric documentation of a project, a Vernacular house in Aksaray, Turkey. The field work and geometric documentation process are described in detail with practical difficulties. The final result is evaluated for the performance of terrestrial laser scanning for geometric documentation of cultural heritage projects, the importance of it for the quality of the projects and its usefulness in this process. 
Opportunities of Geometric Documentation of Historic Buildings with Terrestrial Laser Scanner, Example of a Traditional Turkish House

GEOMETRIC DOCUMENTATION OF CULTURAL HERITAGE

Documentation is a complex process including stages of data acquisition, interpretation, and production. It is the first and the most important step before starting any conservation project. As short definition, documentation is the recording of the existent state and surroundings of the building by reports, drawings and photographs (Yilmaz et. al., 2007).

Heritage documentation is defined by CIPA RecorDiM in 2007 as:

"Heritage Documentation is a continuous process enabling the monitoring, maintenance and understanding needed for conservation by the supply of appropriate and timely information. Documentation is both the product and action of meeting the information needs of heritage management. It makes available a range of tangible and intangible resources, such as metric, narrative, thematic and societal records of cultural heritage" (Santana Quintero et. al., 2008).

As a part of general heritage documentation, apart from the others (architectural, historical, bibliographic documentation etc.), geometric documentation aims to record the present of monuments, as they have been shaped in the course of time (Stathopoulou et. al., 2010). It includes a series of measurements such as vector drawings, raster images, 3D visualizations etc. and metric data acquisition. It mainly aims to define the shape, size and the position of the object in 3D space (Sofocleous, 2006). The geometric documentation of a monument may be defined as (UNECCO, 1972).

- The action of acquiring, processing, presenting and recording the necessary data for the determination of the position and the actual existing form, shape and size of a monument in the three dimensional space at a particular given moment in time.

- The geometric documentation records the present of the monuments, as this has been shaped in the course of time and is the necessary background for the studies of their past, as well as the studies for their future.

The products of geometric documentation have usually metric properties with a series of data, usually at large scales, which fully document the geometric and other properties of the monument in 2D (horizontal and vertical) and in 3D. These produced 3D models can be combined with photogrammetric procedures, such as the production of orthophotos, cross-sections, top and elevation plans, represent the complexity of the monuments in standard metric documents (Stathopoulou et. al., 2010). However the most important properties of these products are their scale and accuracy. They should be carefully defined before any work since 
the scale of the product implies the level of detail (Sofocleous, 2006; Georgopoulos, 2004]).

\section{Geometric Documentation Techniques for Cultural Heritage}

A general challenge in heritage documentation is try to get information with an unsuitable technique. This challenge depends on mainly two reasons; lack of knowledge of available techniques and demand of conservator to use the techniques that he can use alone. If there is not enough knowledge about any technique, it is not preferred to use it even it is the suitable one. Moreover, it is observed that conservators mostly prefer the technique they know well and they can work more alone. Whereas, here, the first step should be understanding the limits of documentation and the utilities of metric technique which helps to balance the information needs of projects with appropriate methods, before starting to documentation (Santana Quintero et. al., 2008).

The main techniques for digitization and geometric documentation of historic buildings and sites can be classified mainly in four categories regarding their methodology. These are:

- Empirical techniques, direct method or hand measurements,

- Standard topographic techniques,

- Close Range Photogrammetry,

- Terrestrial laser scanning (Lysandrou and Agapiou, 2010; Arias et. al., 2005; Andrews et. al., 2013).

Figure 1. Summary of metric survey techniques (Andrews et. al., 2013).
Summary Table of Metric Survey Techniques

\begin{tabular}{l|l|l|l|l}
\hline \multicolumn{5}{c}{ Summary Table of Metric Survey Techniques } \\
\hline \multicolumn{1}{c|}{ Technique } & \multicolumn{1}{|c|}{ Product } & \multicolumn{1}{c}{ Application } & Constraints in use \\
\hline $\begin{array}{l}\text { Direct } \\
\text { Method }\end{array}$ & 2-D & $\begin{array}{l}\text { Key detail records, } \\
\text { explanatory } \\
\text { diagrams. }\end{array}$ & $\begin{array}{l}\text { Structural notes, } \\
\text { architectural definitions, } \\
\text { excavation records. }\end{array}$ & $\begin{array}{l}\text { Selection of } \\
\text { information based } \\
\text { on subjective } \\
\text { domain knowledge }\end{array}$ \\
\hline Topography & 3-D & $\begin{array}{l}\text { CAD frames, point } \\
\text { data. }\end{array}$ & $\begin{array}{l}\text { Topographic mapping, } \\
\text { plans and sections. } \\
\text { Precise control network } \\
\text { measurement. }\end{array}$ & $\begin{array}{l}\text { Date organization is } \\
\text { need by code. Layer } \\
\text { or GIS protocol, } \\
\text { trained operators }\end{array}$ \\
\hline $\begin{array}{l}\text { Close Range } \\
\text { Photogramme }\end{array}$ & 3-D & $\begin{array}{l}\text { Photo-maps, CAD } \\
\text { Drawings, anti- } \\
\text { disaster reports. }\end{array}$ & $\begin{array}{l}\text { Architectural Façade } \\
\text { Drawings, Ortho-photos, } \\
\text { stereo pairs, surface } \\
\text { models. }\end{array}$ & $\begin{array}{l}\text { Calibrated Camera, } \\
\text { optimized image } \\
\text { capture, object area } \\
\text { control, processing }\end{array}$ \\
\hline $\begin{array}{l}\text { Terrestrial } \\
\text { Laser Scanner }\end{array}$ & 3-D & $\begin{array}{l}\text { Point Clouds, } \\
\text { Surface Modes. }\end{array}$ & $\begin{array}{l}\text { Building Models and } \\
\text { Drawings }\end{array}$ & $\begin{array}{l}\text { Point Density must } \\
\text { be matched to } \\
\text { required } \\
\text { information } \\
\text { outcome. }\end{array}$ \\
\hline
\end{tabular}

Direct method or empirical technique is mainly based on the $m$ easurement of reference points on structure, so accuracy of drawings depends on complexity and shape of the object. It is still widely used owing to its low cost and no need for any special expenses for equipment, software etc. Besides this technique is more preferred for 2D drawing and can be used very effectively where the site is accessible, not too large and easy to overlook 
(Boehler et. al., 2002). Topographic measurement is a process of measuring reference points of the structure with total station and it can be performed with high accuracy. 3D point cluster can be obtained by this technique for drawing of structures. However topography cannot provide high density point clusters in a short time. Furthermore, when it is needed to get high resolution data for complex structures like archeological area or ruins, only topographic measurement is inadequate. For complex structures it is needed detailed and reliable 3D models which can be provided by photogrammetry through image-based modeling and Terrestrial Laser Scanning (Salonia et.al, 2009). As a low cost technique, photogrammetry is used with topographic support for documentation purpose in different scales for architectural projects, especially in survey of building façades. Another technique laser scanning technology provides great opportunity for presentation and visualization of cultural heritage with high accuracy in addition to measurement.

\section{Terrestrial Laser Scanning for Geometric Documentation}

Terrestrial laser scanners have become widely investigated instruments among architectural and archaeological surveying applications in last years. Basically, a laser scanner collects a large range of data representing three-dimensional coordinates and called "point cloud" data. The point cloud is a collection of X, Y, Z coordinates in a common coordinate system that defines to the viewer an understanding of the spatial distribution of an object. They may also include additional information, such as return intensity or color values. In order to abstract geometry, shape, measurements and texture of an object. These large amounts of data must be processed in appropriate software which helps to handle huge amount of data and to combine the image and scanned data (Amans et. al., 2013).

Main reason for terrestrial laser scanning technique to become widely used is its data acquisition process. It allows to collect a great amount of data with accuracy supporting reconstruction and repair activities withal analysis of structures. While it is easily possible to detect complex geometries and details in practices requiring sensitive and high accuracy and deep study in constructive techniques, it is difficult to achieve these results with traditional methods (Vacca et.al., 2012). Using of laser scanner with photogrammetry and topography together directly affect the final accuracy of documentation process and results in positive way (Meyer et. al. 2007). It can be compared sensitiveness and using area of these main four techniques in Figure 1.

The survey of an architectural building, besides its complexity, is an act of getting knowledge aiming to understand all details in 
order to get analysis of whole building (Docci and Maestri, 2010). Here the laser scanning technology helps to this analysis by containing data about whole structure in terms of the shape and conservation and restoration of the structure (Lourenço et. al., 2010; De Matías et.al., 2013).

As known, geometric survey is fundamental stage of restoration process (Salonia et.al., 2007). Before any intervention, the restorer needs to get deep and complete knowledge of the cultural property such as measurement, shape and cultural values (Genovese, 2005). It contains different sort of data and is essential to have "accurate knowledge-based model" of the building which includes collected data related to building material, character, decays, interventions and restoration works in the past and information from archival studies about the structure (Canciani, 2013). Laser scanning technology helps to complete geometric and material data of the structure so it contributes to protect authenticity of historic structure by transferring this data significant for restoration (Versaci and Cardaci, 2011). Acquired data, can also be categorized and managed using with GIS which allows us not only to have a "clever" catalogue also to get a useful tool enabling to compare the building's situation at different stages and times; such as before and after restoration, the evolution of the interventions, damages caused by a disaster, etc. (Andrés and Pozuelo, 2009; Oreni, 2006). It should be considered that intervention decisions based on true knowledge acquired by laser scanner directly affect the quality of restoration activities.

\section{Challenges of Laser Scanning}

Even though laser scanning technology replaced some of traditional methods in heritage documentation, sometimes its capabilities are over-rated. Here it is important to consider limitations and capabilities of laser scanning. There are some points to be considered in processing workflow of laser scanning.

Experience in data acquiring is very essential for a successful field survey. In many cases, it is almost impossible to get a complete cover of the structure because of some unachievable parts and conditions. For required level of detail, the parameters should set up very carefully considering the complexity of the structure. When the structure is complex, it is more difficult to get sufficient overlap for data registration. Besides, target distributions on the structure surface and to arrange their visibility are essentially important for overlap. Here also choice of scanner positions, to set right angles and parameters become significant for a successful data acquiring. 
In data registration step in which all scans are put into a single coordinate system is an important step since the accuracy is achieved in this stage. For a satisfied registration, targets should be in high resolution means it requires a lot of field time. Besides time, it's quite difficult to manage high resolution data that sometimes can cause hard and software problems. So registration phase should be considered as crucial part of the modelling process. Similarly, after registration of data, cleaning of point clouds should be done carefully. In this step, it is possible to lose the information about the closest point neighbors which is necessary for surface model.

In this study, difficulties and advantages of using laser scanning technology during documentation projects were evaluated with a case study in Turkey, besides discussion for the advantages of laser scanner for future works and studies were discussed.

\section{CASE STUDY}

Turkey is a reach country in point of cultural heritage in different size and character. These architectural heritage have different character, building materials constructions techniques and deformation reasons in different regions of country. Aksaray is a significant city with its vernacular architecture and interesting landscape (Figure 2, Figure 3). Its traditional houses are generally two-storey masonry buildings and they have different size of spaces and impressive façade designs. In addition, a large number of carved early Christian settlements and churches/chapels take place in some valleys around the city Large number of restoration projects are prepared by architects, are approved by conservation board and are applied by private companies or other institutions in each year. These projects are generally prepared with traditional methods (total station and sometimes direct methods). At the end, it is possible to see some accuracy problems and observe non-overlapping between some drawings and the building.

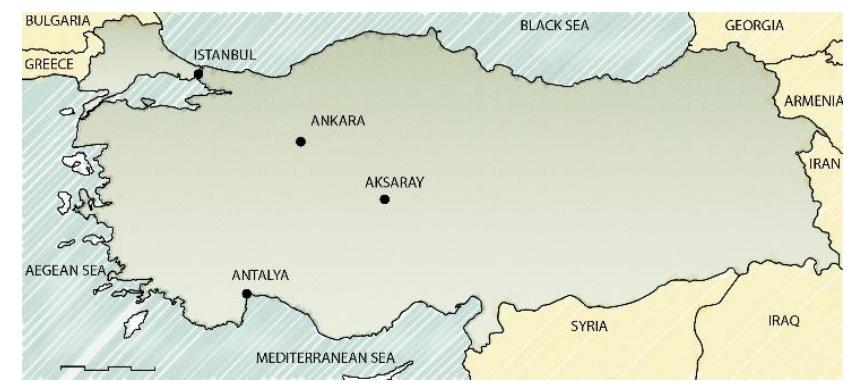

Figure 2. Location of Aksaray. 
Figure 3. Some building typology and architectural heritage in Guzelyurt/Aksaray
S. Armağan Güleç Korumaz \& Grazia Tucci \& Mustafa Korumaz \& Valentina Bonora
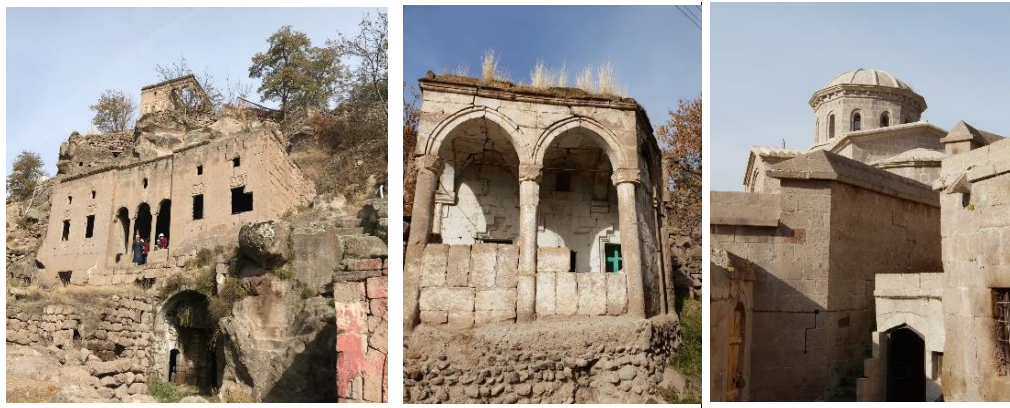

In this study, a middle-scale historical building was chosen from Aksaray, a city close to Cappadocia Region for exemplifying laser scanning use in Turkey for documentation of architectural heritage. In decision process of case study, it was considered that the example should be in dense urban fabric and had different dimensions of spaces with different light amount (Figure4). Thus, it was encountered to find some solutions for different problems during the scanning process. This building was registered as a cultural heritage of Aksaray and it was an aim to re-use it with a new function.

\section{Methodology}

Data accuracy and measurement work have been shown in Figure 5 as methodology of case study. As a first step, topographic survey was carried out in local coordinate system, then several scans were performed around and inside of the building. After scanning and data acquisition, post-processing procedure was followed, and laser scanning data was referenced with topography in office. Afterward, some architectural elements, plans sections, elevations and ortho-images were prepared and were exported to CAD for drawing. 3D model of historical building could be produced in two-different steps for different aim and result: One method is that mesh model could be produced from point cloud and then this mesh model could be texturized with images. As second way, 3D model could be obtained with parametric solid elements. All documents could be stored in a database for current and future use and this data could be managed with GIS applications.

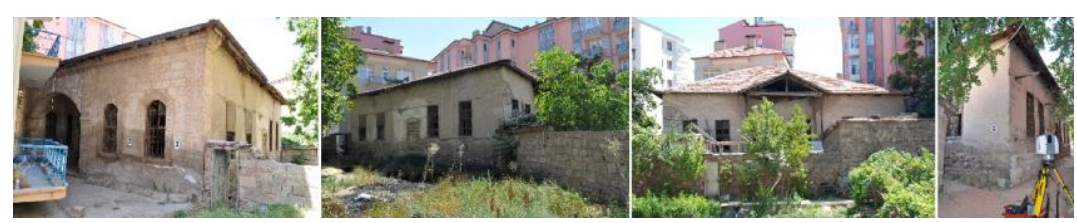

Figure 4. Pictures of the house facades 


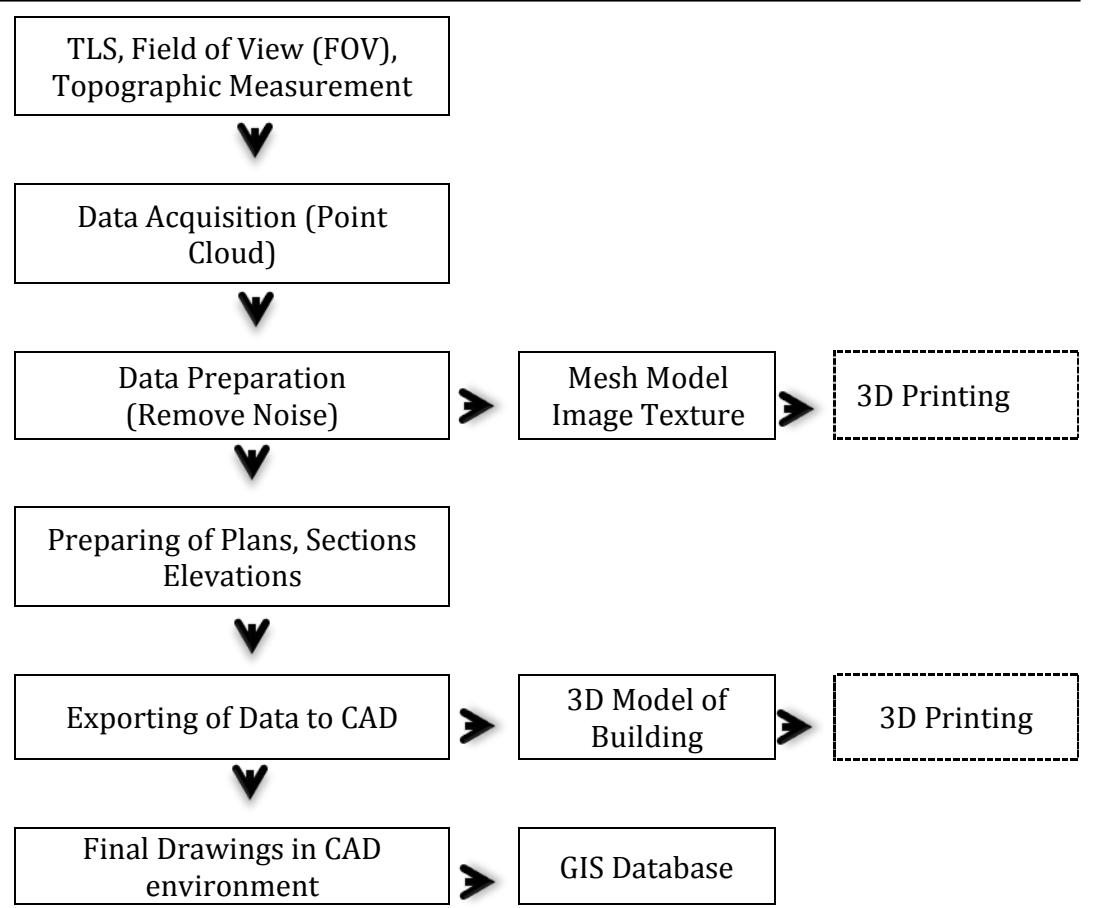

\section{Equipment and software}

The scanning of the building was accomplished by using terrestrial laser scanner Leica Scan Station 2. It is a pulse-based time of flight scanner with a maximum range of $300 \mathrm{~m}$. Its nominal accuracy is $6 \mathrm{~mm}$ at $50 \mathrm{~m}$ and can record up to 50,000 points/sec. The field of view of the scanner is $360^{\circ} \times 270^{\circ}$. It includes a digital video camera of low resolution. Its physical dimensions are 265 $\mathrm{mm} \times 370 \mathrm{~mm} \times 510 \mathrm{~mm}$ and it weighs $18.50 \mathrm{~kg}$. It comes with the proprietary software Cyclone for processing data (Leica, 2013).

Reflectorless Leica total station was used for topography measurements and for targets which were used as reference points for registration of different scans. Nikon D90 with $24 \mathrm{~mm}$ fixed lens was used for taking picture of historical building. Topographic data was adjusted with MicroSurvey StarNet. Cyclone 8.0 was used as main software for data processing, registration of different scans, cleaning of unnecessary data. Cyclone 8.0 was also used for creating and exporting orthoimages. Thanks to Leica CloudWorx plugin, point cloud was able to open in AutoCad. In order to prepare and draw sections, plans and elevations in AutoCad.

\section{Scan Data Collection}

A sketch of the building was prepared to organize workflow of study. Laser scanner positions and topographic network locations were planned on this sketch. Traverse stations were fixed with nails, measured and registered on sketch to easily recognize for next time study.
Figure 5. Methodology of case study. 
In order to enable indirect target-to-target registration (Van Genechten, 2006), black and white targets were located on suitable walls that can be registered and visible from more than one scan location. Totally 30 targets were fixed inside and outside walls of the building and around the buildings facades. Although, reflective and HDS targets could be used in laser scanner applications, A5 size black and white targets were used in this study. Since targets can be automatically recognized in point model, they were used to accelerate alignment procedure and allowed the alignment among data acquired from different rooms. Due to the small doors it was impossible to obtain a high percentage of overlapping. Historic house space sizes are different from each other and distances from scanner to object are different as well. These differences, as expected, affected point cloud density however an equal scanning resolution was set. Redundancy of data allowed in any case to have 1 point per centimeter in the final model. And a lot of picture was taken for documentation of the building and 3D model texturing.

Scanning of the house was performed from 13 different scan positions. Average scan time for each station was 25 minute then additional a few minutes was spent for taking photo for texture mapping of scan data with internal camera and totally 12 hours was spent for 13 laser scanning stations and topographic measurement. During taking photo, even the light of the environment is important for quality of pictures, dark spaces, transparent surface or some part from scanning area from where light directly comes to laser scanner made big problem for homogenous exposure texturing. The big challenge with photography especially for panorama pictures was that different light conditions around the scanner caused over exposure or dark texturing on some parts of point cloud. In order to deal with this problem, users would measure lighting conditions for every scans and determine exposure settings for good average results (Figure 6). 


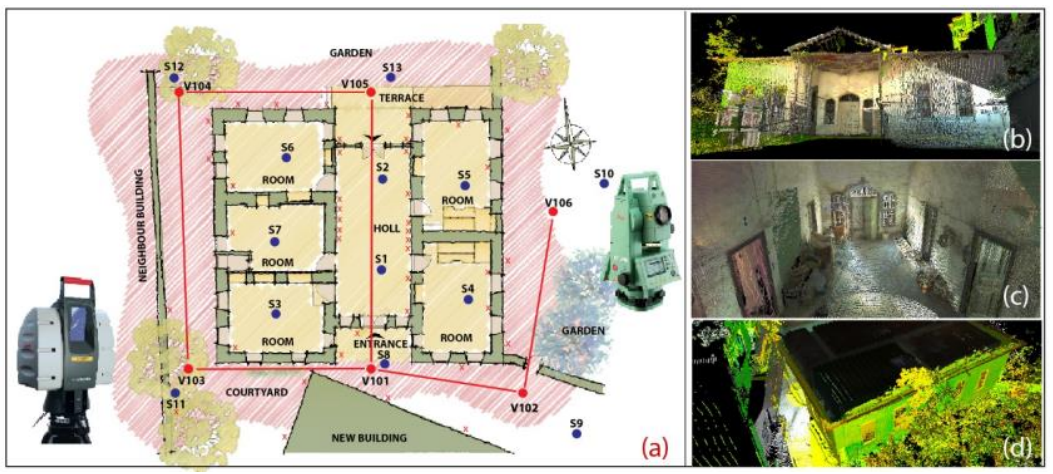

Distance between laser scanner and surfaces of the building directly effects the resolution of point cloud data besides, the rays coming from laser scanner and surface of the object have influence on the quality of point cloud as well. If this angle becomes so acute, resolution problems and noisy parts can be observed. Due to narrow space between the historical building and its neighboring building, some noisy area was observed in point cloud of west façades of the building. On account of these problems, it is needed to get support from direct methods to complete survey in less than $1 \mathrm{~m}$ scanning distances.

\section{Data Processing}

This step includes the works held in the office after scanning. As a first step, topographic data was downloaded from total station and was processed in MicroSurvey StarNet software to adjust the traverse coordinated. Scan data was downloaded from scanner via FileZilla open software.

All scanning data and topographic coordinates were transferred in Cyclone. Registration, which is the process of integration of different scans into a single coordinate system was made in Cyclone point cloud software. This integration is obtained by constrains which are pairs of common points (tie-points) between two scan or overlapping point clouds that exist in two different scan data (Loannides, 2010). In this case study, different scans were registered in a single coordinate system thanks to the target coordinates. This was considered the most suitable method of registration in order to minimize the errors (Andrews et. al., 2013). Since some target points were not distinguished efficiently, considering the registration results, some target points were excluded from registrations. Generally it is important to get error of registration value less than $1 \mathrm{~cm}$. In this case study, after careful registration, $0.004 \mathrm{~m}$ was obtained as registration value. After registration, 100.446.404 number of point in total was acquired. The size of the scanning files (imp files) reached $110 \mathrm{MB}$.

Point cloud contains all data obtained by laser scanner. It is necessary to clean some part of point cloud not directly related to the structure. In this case study, also some part of point cloud were not related to the historical house so they were cleaned and
Figure 6. (a): Topographic network of fieldwork (b): Point cloud view of south façade. (c): Point Cloud view from inside of building. (d): Perspective view of the house. 
the total number of points was reduced to 97.578.840. Sometimes it is very difficult manage all point cloud so data reduction can be preferred for easier management of the model. However, a global point cloud reduction is not recommended before complete back up all data, since it entails information lost (Lerones et. al., 2010). Noise reduction is generally random and unfortunately accompanied by a loss of detail. Noise typically increases in overlapping areas (Rühter et.al, 2011).

\section{Preparation of Plans, Sections and Elevations}

After the registration, all scan data became in common coordinate system and this coordinate system can be transformed to local ones according to final results of section, elevation and plan layouts. This transaction was done by utilizing UCS (user coordinate system) in Cyclone software. Reference tree points which would recognize XYZ directions were used for transforming coordinate system in Cyclone for preparation of measured drawings of Aksaray House (Figure 7).

In Turkey, number of the section depend on object complexity but generally two sections (one cross and one longitudinal) are main requirement for restoration projects When restoration projects are prepared with point cloud model, different plans and sections with different locations can be obtained as needed. It is possible to manage the thickness of slices in order to recognize all of the plan end section details. In this case study slice thickness for plan layouts are $0.01 \mathrm{~m}$ and the main section elevation is $1.5 \mathrm{~m}$ according to ground level of historical building. Ground cover detail and ceiling projection can be drawn colored point cloud with changing view direction of plan section. In this study, slices were exported to CAD software as DXF format and views of ground covers and lining of ceilings were exported to AutoCad as TIFF format ortho-image. Similarly, some temporary coordinate systems parallel to building façades were prepared for elevations. Unnecessary point clouds for facades drawings were hidden. Orthographic views were obtained and were exported to AutoCad as TIFF orthographic images (Figure 7, Figure 8). 
Opportunities of Geometric Documentation of Historic Buildings with Terrestrial Laser Scanner, Example of a Traditional Turkish House
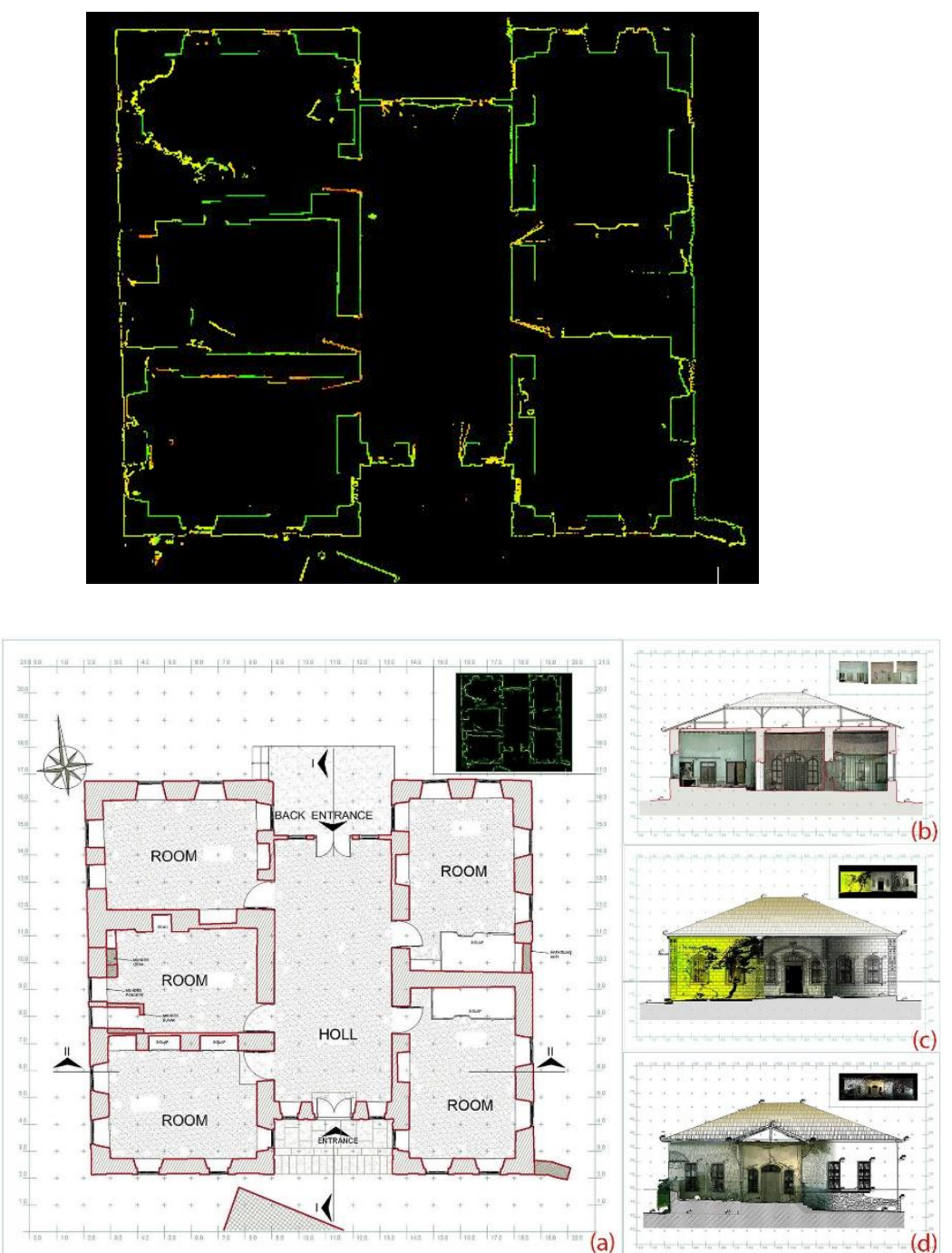

All ortho-images exported from Cyclone contain georeferences data thanks to some collateral files (TWF, TFW extensions). When these images are imported into AutoCad, thanks to some special tools, these images can be taken places according to coordinate system coming from Cyclone.

$3 \mathrm{~d}$ documentation is getting common in Turkey documentation main study field. Archeological areas and architectural ruins are a good works for 3d documentation techniques. Especially TSL is effective solutions for survey projects in Turkey (Figure 9,10,11).
Figure 7. Horizontal section of plan for drawing of plan layout.

Figure 8. (a) Plan of building with exported points from Cyclone as dxf to Autocad. (b) One Section of Building. (c) South elevation drawing with orthoimages. (d) North elevation drawing with ortho-images. 
Figure 9. A Mass stone building main façade ortho-image from pointcloud in Guzelyurt/Aksaray

Figure 10. Aksaray Kılıçaslan Hammam, in city center. After excavation 3D documentation

Figure 11. Documentation of completely ruined semi caved traditional Guzelyurt/Aksaray
S. Armağan Güleç Korumaz \& Grazia Tucci \& Mustafa Korumaz \& Valentina Bonora
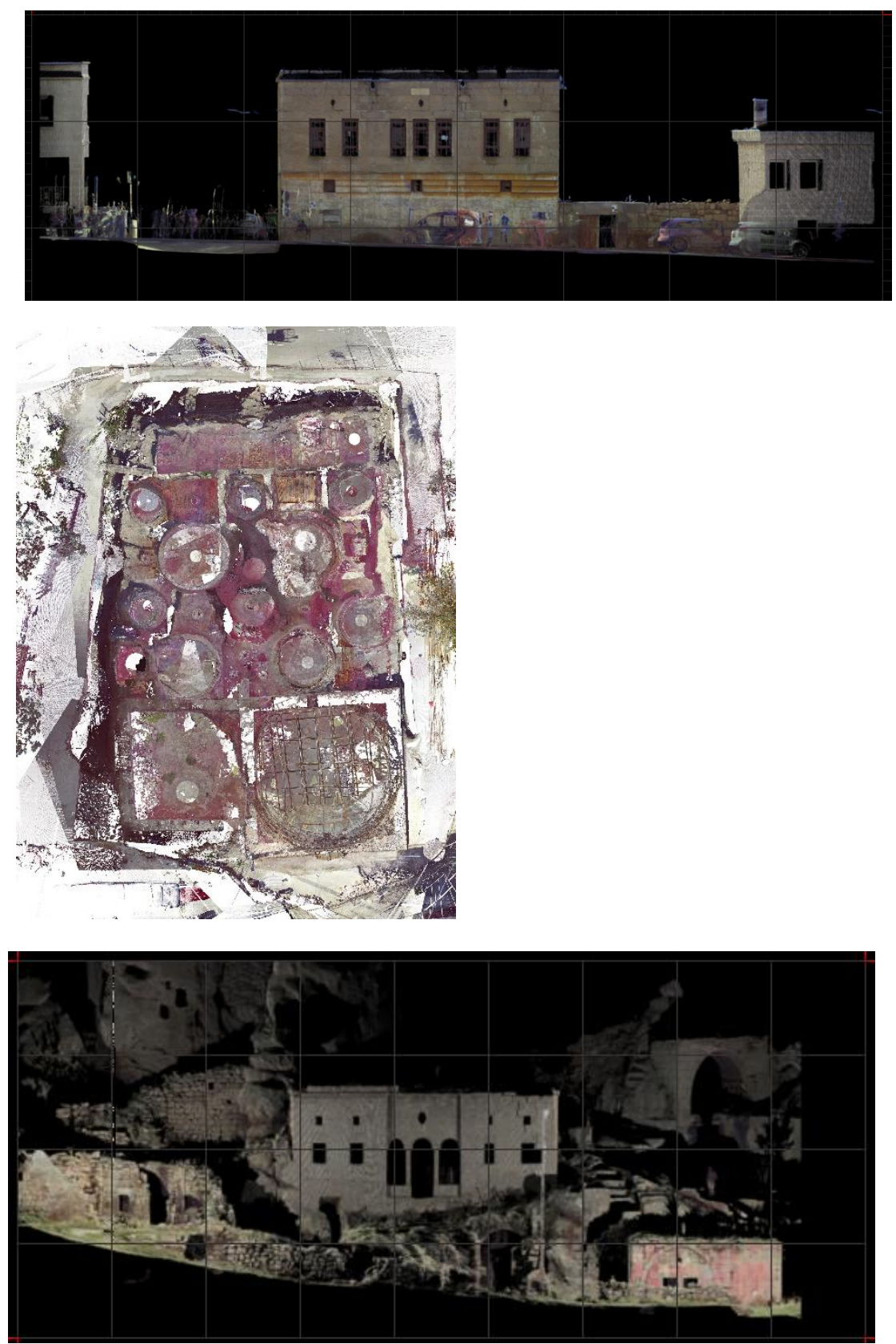

\section{Modelling}

Far from their physical locations, buildings can be visualized, perceived and understood thanks to digital 3D modeling (Balzani et.al., 2012). With the advent of digital modern techniques for 3D acquisition, it has become possible to drape images on the point clouds of objects. Producing of 3D models based on geometric data in architectural surveys has led to develop different data collecting and sharing methods in cultural heritage studies. Generally parametric $3 \mathrm{~d}$ models are used for expression of some ideas using with some measurements from point cloud (Figure. 12). This models don't need to convert point cloud to the mesh models. There are principally two main reasons to convert point cloud data to mesh models. First, mesh models can be used in different graphic software for different aim and they can be easily 
published via internet. For the second, mesh models are generally used in 3D printing technology (Stnik et.al., 2010). Scanned objects replicas can be reproduced with different materials and different scales thanks to 3D printing. There are some difficulties to share high-resolution 3D models generated by point cloud via internet. However, some softwares provide suitable solutions to share high-resolution 3D models without losing visual characteristics (Valanis et.al., 2010). 3D textured models are generally used for giving information about the object (as in multimedia museums, exhibitions) and sharing or dissemination of information and using as a data for professional studies (Tucci et.al, 2012). Two survey methods, laser scanner and photogrammetry are very effective 3D reconstruction techniques but recently, low cost techniques also allow the fully automatically three-dimensional reconstruction of objects from images, giving back a dense point cloud and a surfaced mesh model (Fassi et.al., 2013). The image-based approach is generally considered a lowcost method (in particular for Terrestrial applications) (Romondino et.al., 2012).

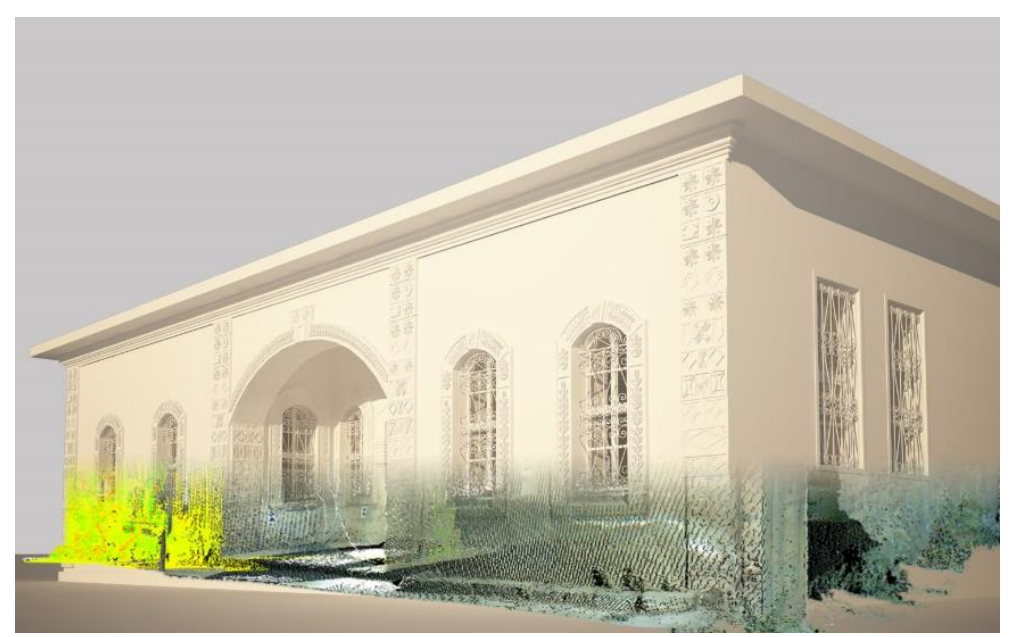

Figure 12. 3D Cad model of houses base on point cloud data.

These 3D results can be used for many purposes, such as archaeological analyses, digital preservation and conservations, computer aid restoration, virtual reality or computer graphic applications (Rizzi et.al, 2011). 3D models can be integrated with multi discipliner studies (Cappellini and Campi, 2011). Calibrated and orientated high-resolution digital images provide scan and image data. This data can be automatically or semi-automatically processed to generate product such as textured triangulated surfaces or ortho-photos with depth information (Koska and Kremen, 2011; Neubauer et.al., 2005). 3D models with exhaustive graphic-communications makes them easy to understand and they show objects with fundamental and irreplaceable value (Lamatina and Lanfranchi, 2013). 
Any laser scanner usually comes with specific software for data acquisition and processing. The capabilities of these software vary but generally they can process acquired data (filtering, cleaning, alignment ect.). Also 3D mesh models can be obtained by other specific programs for mesh modeling (Rapidform, VRmesh). Additionally different open-source software offers alternative free solutions for users (Callieri et.al, 2011).

In this case study, only façades of historical building were modelled. Point cloud was exported from Cyclone as PLY extension and opened with open software MeshLab for triangulation process. These kinds of projects require powerful computers with fast processors and graphic cards. Otherwise great amount of time could be lost for that process. Point cloud data could be segmented and $3 \mathrm{~d}$ modeling of object could be made part by part (Fassi et.al, 2011). Cleaning of unnecessary point cloud data and size of triangulation can be managed with MeshLab software. After creating mesh model, it is generally necessary to fill some holes, to repair some part of the model and to make some model optimization. After texturizing mesh with photos, $3 \mathrm{~d}$ model of object can be used for any desired purposes (Figure 13). In recent years, TLS has shown great versatility for also 3D printing. The data of TLS gives possibility to print 3D models for different purposes with diverse materials. These printed models can be either small objects or complex buildings or sites (Figure 14).

Figure 13. Texturized part of 3D model of building with images for obtained photorealistic model.

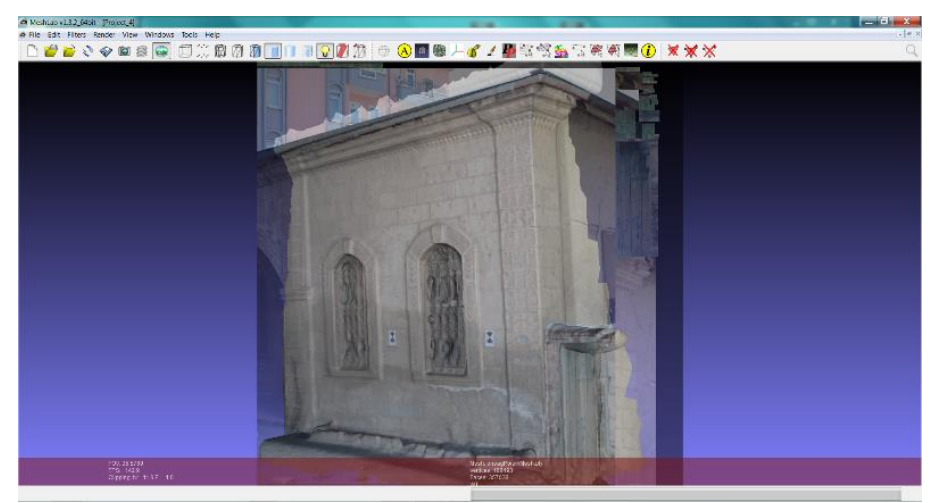




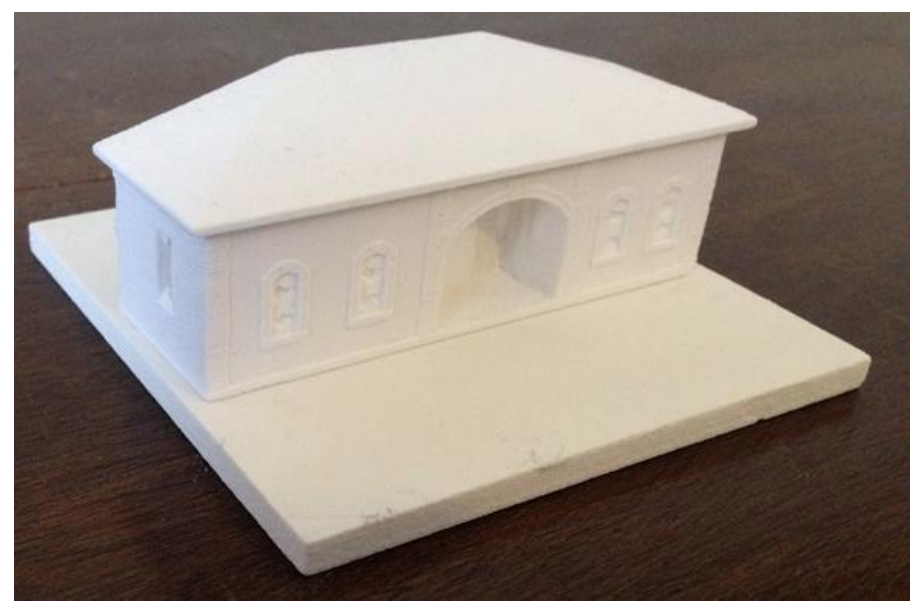

\section{Virtual Panoramic Tour}

Technological developments in recent years have remarkably increased the diversity of metric data collection methods. With the help of advancements in computer industry, three dimensional visualizations of the monuments have been facilitated in a virtual world. The collection of data for 3D models of historical monuments is simplified by dense point clouds created by terrestrial laser scanners.

Virtual Reality (VR) is a development of the artificial (man-made) based computer technology that can be controlled by the user using the mouse. VR interactive key points lies in the hands of the user controls the enjoyment of photos by moving the mouse or by pressing the keyboard (Prabawati and Triyuliana, 2006; Famukhit et.al., 2013).

In the last years virtual reality tours have been created for both simple and more complex monuments. This ability has greatly contributed to the thorough study of the monuments, as well as to the creation of virtual visits (Sofocleous, 2006).

Virtual models are fundamental media tool which allow users to interact with 3D models in a virtual environment. In last decades, virtual tour applications prepared with panoramic images have been started to be applied in cultural heritage field for documentation, preservation, reconstruction, decision support and cultural heritage promotion. Especially in field of archeology, virtual models enrich interactivity and visualization (Pavlidis et.al., 2007) This makes them to become powerful tools for visualization and 3D reconstruction of archeological sites and finds (Bruno et.al., 2010) as well as sustainable tourism and cultural heritage management (Lettelier, 1999). Increasing number of visitors have negative effect on cultural heritage when it is thought to protect cultural heritage. In contrast, tourists and

Figure 14. 3D Printed images of building for different purposes. 
tourism companies, even the countries, would like to promote their cultural heritage for more visit. Virtual tours may be seen as a kind of solution for this concern since they give the possibility to visitor to have visiting experience. With the possibility of displaying 3D models of cultural heritage, one can able to visualize, zoom and make walkthrough of these models by rotating. To promote the cultural heritage is not the only contribution of VR to cultural heritage field. Beside documentation and recording, it also helps to give information about lost heritage, to support education process at architectural schools, to present tradition and culture throughout the cultural heritage, to develop learning experiences with expert and nonexpert stakeholders (Reffat and Nofal, 2013). Another advantages of virtual panoramic tours could be for conservators. In some cases, it can become very difficult to see the cultural heritage for several reasons like safety or distance. At the same time, since they are also decision makers for cultural heritage, it can be useful to have such a kind of system especially shared on a database or web-site for decision makers (Figure 15).

Figure 15. Different screens from panoramic tour of house.

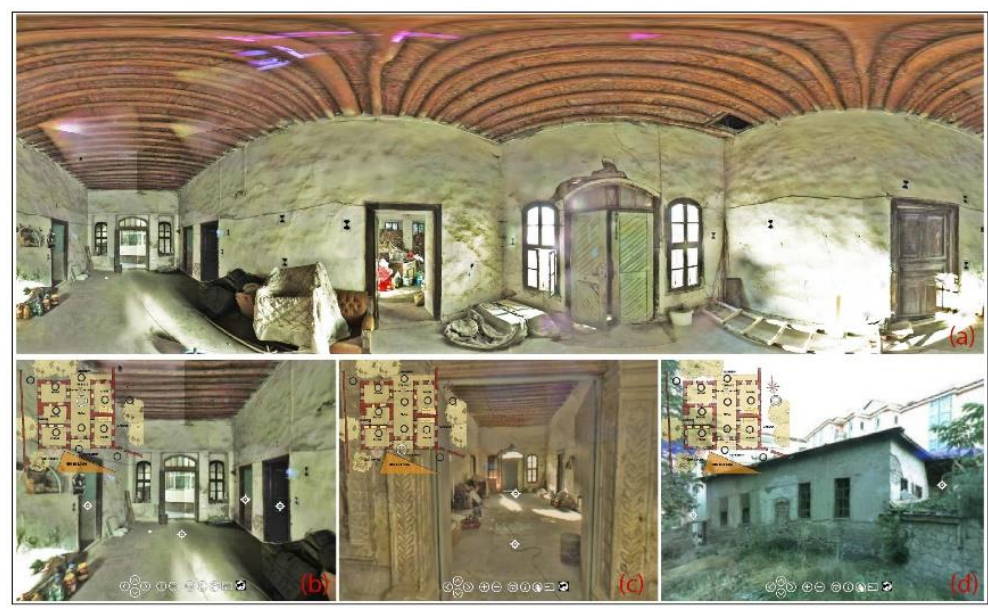

It could be said that over the last twenty years, special recording tools like photography, architectural stereo-photogrammetry, 3D modelling and 3D laser scanning techniques only or integration of these techniques can be used in the field of cultural heritage. A simple but efficient option for the visualization of a complex objects is the virtual tour using panorama photography (Kersten and Lindstaedt, 2012). In this study a panoramic tour was prepared with the photos from laser scanner. For colorizing the point cloud of the Leica Scan Station 2 panorama photographs were taken from each scan station using a nodal point adapter for the camera on the tripod of the laser scanner. This images can be exported from Cyclone as JPG extension. The software PTGui automatically generated a spherical panorama with $640 \times 480$ pixel for each camera station. These panorama images were converted into a set of six cube and simultaneously generated one 
interactive virtual tour for all available panorama images with Pano2VR.Hotspots, overview maps, photographs, text, music, videos and many more custom actions can be integrated with this software.

\section{DISCUSSIONS}

With experience of this case study, it can be said that laser scanner has been used in surveys, due to its high speed data collection and processing, high density and accuracy of measured points, advantage of time of analysis; its contribution helps to increase the productivity (Mamede et.al. 2012). This dense data is successful to recognize the shape of architectural objects and its anomalies as distortions, asymmetry, and out of plumb of building structure (Haddad, 2011). Not only for time processing and analysis, but also for the richness of detail, once this system is able to capture topographic information in inaccessible places such as ceilings and irregular galleries, in the case of monuments, or even in places difficult to visualize, in case of the sculptures and / or works of art (Rühter et.al, 2012). Data capture without any physical access to a structure is of a special interest in the case of historical buildings due to the peculiarities of their construction and location. Detection of material degradation on historical buildings using traditional methods manual mapping, or "naked eye" analysis performed by an expert, is laborious and time consuming procedures (Armesto-González et. al., 2010). 3D modelling and ortho-image support to give different initiative for documentation of cultural heritage. Possibility of sharing 3D models via internet provides data management and dissemination of information about cultural heritage. Thanks to sharing data, 3d models and internet access aid to close gap between the data supplier and data users (Lourenço et.al., 2010).

Speed of laser scanning applications predictably depends on device working principle but in any case these systems are faster than traditional measurements techniques. Also, scanning time for each position depends on the preferred scan resolutions. Opportunity of convenience and speed of laser scanning applications can easily be observed especially when the shape of the object is complex.

While topographic measurement and direct measurement techniques help to measure specific points of buildings in detail, laser scanner acquires data related to whole of the objects and gives possibility to store data. This is an important advantage when compared with conventional techniques. In this way, a lot of data like materials and structural deformations can be stored in digital environment. 
Direct integration of laser scanning technologies with CAD software also facilities architectural drawings. Ability to manage point cloud in CAD software thanks to special tools, all architectural layouts can be directly prepared in CAD softwares, is among other advantages of these techniques.

Laser scanner and post processing software's costs are expensive and it is another difficulty to get the technology because of the cost except hiring from private companies. However, it may be seen another problem increasing project cost to employee technical staff for managing the data. Although, laser scanning technology is expensive, in long term period and with taking into account of its accuracy, to use this technology gives advantage to users.

Use of laser scanning technology has become more widespread almost in all area related to cultural heritage and engineering applications requiring high accuracy spatial data. In spite of this prevalence, use of laser scanning technology has been still limited in restoration projects in Turkey despite Turkey is a rich country with its cultural heritage. Even though there are many disciplines strongly need this technology related to architectural field and may carry out a large number of applications, the use of this technology by expert and private companies has been still low in Turkey. The main reasons for this low utilization using rate can be defined as: lack of integration into architectural education, difficulties to get technology and deficiencies in the legal arrangements for use of laser scanning data in architectural documentation process.

It could be mentioned that there are limited number of expert academic staff, courses and equipment related to laser scanner technologies, only in a few universities of Turkey. For this reason, this topic is almost not included in bachelor degree level; however it could be a research field for a master and doctoral study or may take place in some research projects in a limited number of universities. These kinds of studies are generally carried out with providing supervisors and equipment from departments of geomatics engineering. Hence, the use of the software and instrument can be mostly learned only through personal effort and work experience. As secondary, financial aspect is another restriction about this technology. Laser scanning hardware and software products used in applications to be seen as expensive, requirement of employing qualified staff are thought as factors increasing the cost of the project. For these reasons, private companies do not intend to invest in this technology so much and they prefer to use their best known techniques on their project, considering the costs. Thirdly, there is not any binding legislation for the projects intended for using laser scanning or 
photogrammetric data in Turkey. It is specified only in a few number of official tenders as prerequisite to use laser scanning data. Any special measurement method is not defined as a prerequisite for the remaining tenders and bidders choose their measurement techniques for preparation of the project.

\section{RESULTS}

It is clear that use of this technology provide a significant contribution to conservation practices in Turkey. This technique rather than just a measurement method contains an extensive research on historical buildings. It is observed that data which are very difficult to acquire with conventional methods, can be obtained by laser scanner in a short time with high accuracy. Thanks to 3D models, great number of data can be shared via internet. Because of the fact that laser scanner technology provides some facilities to extract sections and elevations from point cloud, it gains advance to conservation projects. While there are some difficulties in narrow spaces, in general, good results were observed in the end of case study. Especially, it can be said that laser scanning technology is effective as non-destructive method for archeological areas and all buildings.

In order to get common use of laser scanning technology in restoration projects in Turkey, it has been concluded that adequate training should be given in universities, workshops should be organized by relevant organizations, and especially, this technology should be taken place in architectural education. It is also observed that, to hire laser scanner seems as an alternative solution to get this technology for avoiding high cost of equipment and software in Turkey. Use of laser scanner or photogrammetry should become prerequisite for preparation of conservation projects, and for current restoration projects and some arrangements should be done in legislations. Although, at the beginning, investment is so high for private companies or institutions, when price-performance comparison did laser scanner technology is very effective method in long term period.

\section{REFERENCES}

Amans, O. C., Beiping, W., Ziggah, Y. Y., \& Daniel, A. O. (2013). The need for $3 \mathrm{~d}$ laser scanning documentation for select Nigeria cultural heritage sites. European Scientific Journal, ESJ, 9(24).

Andrés, M. A. N., \& Pozuelo, F. B. (2009). Evolution of the architectural and heritage representation. Landscape and Urban planning, 91(2), 105-112. 
Andrews, D., Bedford, J., Blake, B., Bryan, P., \& Cromwell, T. (2013). Measured and drawn: techniques and practice for the metric survey of historic buildings. English heritage.

Arias, P., Herraez, J., Lorenzo, H., \& Ordonez, C. (2005). Control of structural problems in cultural heritage monuments using close-range photogrammetry and computer methods. Computers \& structures, 83(21-22), 1754-1766.

Armesto-González, J., Riveiro-Rodríguez, B., González-Aguilera, D., \& Rivas-Brea, M. T. (2010). Terrestrial laser scanning intensity data applied to damage detection for historical buildings. Journal of Archaeological Science, 37(12), 30373047.

Balzani, M., Bughi, C., Ferrari, F., Rossato, L., \& Tursi, A. (2012, October). Alberti's Box: The Cultural Multimedia Project on the Architectures of Leon Battista Alberti. In EuroMediterranean Conference (pp. 66-75). Springer, Berlin, Heidelberg.

Boehler, W., Heinz, G., \& Marbs, A. (2002). The potential of noncontact close range laser scanners for cultural heritage recording. International archives of photogrammetry remote sensing and spatial information sciences, 34(5/C7), 430-436.

Bruno, F., Bruno, S., De Sensi, G., Luchi, M. L., Mancuso, S., \& Muzzupappa, M. (2010). From 3D reconstruction to virtual reality: A complete methodology for digital archaeological exhibition. Journal of Cultural Heritage, 11(1), 42-49.

Callieri, M., Cignoni, P., Dellepiane, M., Ranzuglia, G., \& Scopigno, R. (2011). Processing a complex architectural sampling with meshlab: the case of piazza della signoria. Proceedings of $3 D-A R C H, 4$.

Canciani, M., Falcolini, C., Saccone, M., \& Spadafora, G. (2013). From point clouds to architectural models: algorithms for shape reconstruction. ISPRS Archives, 5, W1.

Cappellini, V., \& Campi, M. (2011, September). 3d survey of the San Carlo Theatre in Naples. In ISPRS Trento Workshop,(2011) (Vol. 95).

De Matías, J., Berenguer, F., Cortés, J. P., De Sanjosé, J. J., \& Atkinson, A. (2013). Laser Scanning for the geometric study of the Alcántara Bridge and Coria Cathedral. ISPRS-International Archives of the Photogrammetry, Remote Sensing and Spatial Information Sciences, 1(1), 51-56.

Docci, M., \& Maestri, D. (1994). Manuale di rilevamento architettonico e urbano. Roma: Laterza.

Famukhit, M. L., Yulianto, L., \& Maryono, B. E. P. (2013). Interactive application development policy object 3D virtual tour history Pacitan District based multimedia. IJACSA) 
International Journal of Advanced Computer Science and Applications, 4(3).

Fassi, F., Achille, C., Gaudio, F., \& Fregonese, L. (2011). Integrated strategies for the modeling of very large, complex architecture. Proceedings of the International Archives of the Photogrammetry, Remote Sensing and Spatial Information Sciences, Trento, Italy, 2-4.

Fassi, F., Fregonese, L., Ackermann, S., \& De Troia, V. (2013). Comparison between laser scanning and automated $3 \mathrm{~d}$ modelling techniques to reconstruct complex and extensive cultural heritage areas. International Archives of the Photogrammetry, Remote Sensing and Spatial Information Sciences, 5, W1.

Genovese, R. A. (2005). Architectural, archaeological and environmental restoration planning methodology: historic researches and techniques of survey aiming to conservation. In CIPA 2005 XX international symposium, Torino, Italy.

Georgopoulos, A., \& Ioannidis, C. (2004, May). Photogrammetric and surveying methods for the geometric recording of archaeological monuments. In FIG Working Week (pp. 2227).

Haddad, N. A. (2011). From ground surveying to 3D laser scanner: A review of techniques used for spatial documentation of historic sites. Journal of King Saud University-Engineering Sciences, 23(2), 109-118.

http://cipa.icomos.org/fileadmin/template/doc/PRAGU E/147.pdf (accessed, July 2013).

Kersten, T. P., \& Lindstaedt, M. (2012, October). Virtual architectural $3 \mathrm{~d}$ model of the imperial cathedral (kaiserdom) of königslutter, germany through terrestrial laser scanning. In Euro-Mediterranean Conference (pp. 201-210). Springer, Berlin, Heidelberg.

Koska, B., \& Kremen, T. (2013). The combination of laser scanning and structure from motion technology for creation of accurate exterior and interior orthophotos of St. Nicholas Baroque church. Int. Arch. Photogramm. Remote Sens. Spat. Inf. Sci, 40, 133-138.

La Mantia, M., \& Lanfranchi, F. (2013, February). The reverse modelling realized by digital scans and fotomodellazione: based on post-processing compared several noteworthy episodes contained in the basilical complex of San Lorenzo fuori le Mura in Rome. In ISPRS Trento Workshop,(2011) (Vol. 152).

Leica ScanStation 2 technical sheet, available from: http://hds.leica-ecosystems.com/downloads123/hds/hd 
s/ScanStation/brochures/LeicaScanStation\%202_brochu re_en.pdf (accessed: July 2013)

Lerones, P. M., Fernández, J. L., Gil, Á. M., Gómez-García-Bermejo, J., \& Casanova, E. Z. (2010). A practical approach to making accurate 3D layouts of interesting cultural heritage sites through digital models. Journal of Cultural Heritage, 11(1), 1-9.

Lettelier, R. (1999). Virtual reality... A new tool for sustainable tourism and cultural heritage sites management: Paper presented at CIPA XVII International Symposium Web, Olinda, Brazil.

Loannides, M., Fellner, D., Georgopoulos, A., \& Hadjimitsis, D. (2010). Geometric Documentation Of Historical Churches in Cyprus Using Laser Scanner., In Proceedings of EuroMed2010 3rd International Conference Dedicated on Digital Heritage.

Lourenço, P. B., Peña, F., \& Amado, M. (2010). A document management system for the conservation of cultural heritage buildings. International Journal of Architectural Heritage, 5(1), 101-121.

Lourenço, P. B., Peña, F., \& Amado, M. (2010). A document management system for the conservation of cultural heritage buildings. International Journal of Architectural Heritage, 5(1), 101-121.

Lysandrou, V., \& Agapiou, A. (2010). Comparison of documentation techniques for the restoration and rehabilitation of cultural heritage monuments: the example of Pyrgos "Troulli" medieval tower in Cyprus. In 3rd Int. Conf. dedicated on Digital Heritage, Archaeolingua, Limassol, Cyprus (pp. 21-26).

Mamede, C.G., Silva, B.Q., Schuler, C.A.B. (2012). Laser scanner in works of art and historical monuments monitoring, 8th FIG Regional Conference Surveying Towards Sustainable Development, Uruguay

Meyer, É., Grussenmeyer, P., Perrin, J. P., Durand, A., \& Drap, P. (2007). A web information system for the management and the dissemination of Cultural Heritage data. Journal of Cultural Heritage, 8(4), 396-411.

Neubauer, W., Doneus, M., Studnicka, N., \& Riegl, J. (2005, September). Combined high resolution laser scanning and photogrammetrical documentation of the pyramids at Giza. In CIPA XX International Symposium (pp. 470-475).

Oreni, D., Fassi, F., Brumana, R., Prandi, F., \& Tuncer, H. (2006). Laser Canning supports architectural mappings and historical urban view analysis. In XI International CIPA Symposium. 
Patias, P. (2009). Cultural Heritage Documentation. International Summer School 'Digital recording and 3D Modeling', Aghios Nikolaos, Crete, Greece, 24-29 April.

Pavlidis, G., Koutsoudis, A., Arnaoutoglou, F., Tsioukas, V., \& Chamzas, C. (2007). Methods for 3D digitization of cultural heritage. Journal of cultural heritage, 8(1), 93-98.

Prabawati, T. A., \& Triyuliana, A. H. (2006). Multimedia: Making It Work edisi 6. Yogyakarta: Penerbit ANDI.

R. Sitnik, P. Bolewicki, J. Rutkiewicz, J. Michonski, M. Karaszewski, J. Lenar, K. Mularczyk, W. Zaluski. (2010). Project "revitalization and digitization of the seventeenth century palace complex and garden in Wilanow - phase III" task "3d digitalization of selected exhibits collection"EuroMed2010 International Conference.

Reffat, R. M., \& Nofal, E. M. (2013). Effective communication with cultural heritage using virtual technologies. International Archives of the Photogrammetry, Remote Sensing and Spatial Information Sciences, 5, W2.

Remondino, F., Del Pizzo, S., Kersten, T. P., \& Troisi, S. (2012, October). Low-cost and open-source solutions for automated image orientation-A critical overview. In EuroMediterranean Conference (pp. 40-54). Springer, Berlin, Heidelberg.

Rizzi, A., Baratti, G., Jimenez, B., Girardi, S., \& Remondino, F. (2011). 3D recording for 2D delivering-The employment of 3D models for studies and analyses. Int. Archives of Photogrammetry, Remote Sensing and Spatial Information Sciences, 38, 5.

Rüther, H., Held, C., Bhurtha, R., Schröder, R., \& Wessels, S. (2011). Challenges in heritage documentation with terrestrial laser scanning. In Proceedings of the 1st AfricaGEO Conference, Capetown, South Africa (Vol. 30).

Rüther, H., Held, C., Bhurtha, R., Schroeder, R., \& Wessels, S. (2012). From point cloud to textured model, the zamani laser scanning pipeline in heritage documentation. South African Journal of Geomatics, 1(1), 44-59.

Salonia, P., Bellucci, V., Scolastico, S., Marcolongo, M., \& Leti Messina, T. (2007, October). 3D survey technologies for reconstruction, analysis and diagnosis in the conservation process of cultural heritage. In Proceedings of CIPA.

Salonia, P., Scolastico, S., Pozzi, A., Marcolongo, A., \& Messina, T. L. (2009). Multi-scale cultural heritage survey: Quick digital photogrammetric systems. Journal of Cultural Heritage, 10, e59-e64.

Santana Quintero, M., Blake, B., Eppich, R., \& Ouimet, C. (2008, January). Heritage documentation for conservation: partnership in learning. In The Spirit of Place. ICOMOS. 
Sofocleous, E., Ioannides, M., \& Ioannidis, C. (2006). The geometric documentation of the asinou church in cyprus. In Proceedings of the 7th International Symposium on Virtual Reality, Archaeology and Cultural Heritage, Lefkosia Cyprus.

Stathopoulou, E. K., Lerma, J. L., \& Georgopoulos, A. (2010). Geometric documentation of the almoina door of the cathedral of Valencia. In Proceedings of EuroMed2010 3rd International Conference Dedicated on Digital Heritage.

Tucci, G., Cini, D., \& Nobile, A. (2012). A Defined Process to Digitally Reproduce in $3 \mathrm{D}$ a Wide Set of Archaeological Artifacts for Virtual Investigation and Display. Journal of earth science and engineering, 2(2), 118-131.

U.N.E.S.C.O. (1972). Photogrammetry applied to the survey of HistoricMonuments, of Sites and to Archaeology, UNESCO editions.

Vacca, G., Deidda, M., Dessi, A., \& Marras, M. (2012). Laser scanner survey to cultural heritage conservation and restoration. International Archives of the Photogrammetry, Remote Sensing and Spatial Information Sciences, 39(B5), 589-594.

Valanis, A., Fournaros, S., \& Georgopoulos, A. (2010). Photogrammetric texture mapping of complex objects. In Proceedings of Eur-oMed2010 3rd International Conference dedicated on Digital Heritage.

Van Genechten, B. (2008). Theory and practice on Terrestrial Laser Scanning: Training material based on practical applications.

Versaci, A., \& Cardaci, A. (2011). Web-sharing for a cultural heritage computer database of Central Sicilian monuments. CIPA, ISPRS syposium, Prague, available from:

Yilmaz, H. M., Yakar, M., Gulec, S. A., \& Dulgerler, O. N. (2007). Importance of digital close-range photogrammetry in documentation of cultural heritage. Journal of Cultural Heritage, 8(4), 428-433.

\section{Resume}

S. Armağan Güleç Korumaz (B. Arch, PhD.) is instructor of architecture department at the Konya Technical University. She studied architecture in Selçuk University and got her bachelor degree in 2003. She started to work as researcher in the same university at 2004. She studied photogrammetry and documentation techniques for cultural heritage in her master degree and she completed her MSc in architecture at 2008 in Selçuk University Natural Science Institute. She studied digital documentation techniques, TLS and decision support systems for cultural heritage during her PhD in Selçuk University (2008-2015). 
She got scholarship from TUBITAK (Scientific and technological Research Council of Turkey) in 2012 and studied Florence University Engineering Faculty Department of Civil and Environmental Engineering (DICEA) between 2012-2016. She completed her second PhD about improved documentation techniques in an international joint program collaboration with Florence University (Italy) and Braunschweig Technical University (Germany). She is an instructor at new established Konya Technical University department of architecture.

Grazıa Tucci is an Associate Professor-Scientific Coordinator of GeCo Laboratory. She works in the Department of Civil and Environmental Engineering (DICEA) in University of Florence, in Topography and Cartography field. She's member of the University of Florence Scientific Board for International PhD Program. Her main research topic is focused on the use of Geomatics for the protection and enhancement of Cultural Heritage. She sets up and coordinates the GeCo Laboratory (Geomatics for Conservation \& Communication of Cultural Heritage) and she contributes to multidisciplinary research projects and survey campaigns on both National and International levels, for Public Administration and Private Institutions. She has been scientific coordinator of several research projects and commissioned in the field of geomatics applied to Cultural Heritage documentation.

Mustafa Korumaz obtained his Bachelor Degree from Selçuk University Department of Architecture in Konya (Turkey) in 1999. He got his Master Degree with title Examination of new additions to historical buildings: examples from Istanbul in Selçuk University Natural and Applied Science Institution in 2003. He got his PhD degree with title Evaluation of Façadism Applications on Historic Buildings in Context of Conservation in Turkey in Selçuk University Natural and Applied Science Institution in 2011. He workd in Italy, for his post-doctoral study about the items New Additions on Historical Building and Environment and Façadism under the supervision of Prof. Maurizio De Vita and also, Laser Scanning Technologies for analyzing of historic structures with Prof. Gianni Bertoli in Florence University. He has taught in Selçuk University since 1999. He generally working on restoration and adaptation of historic buildings, new design methodologies in historic buildings and environments, documentation of historic buildings.

Valentina Bonara (B. Arch, M.Sc, Phd) graduated cum laude (outstanding degree) in Architecture at the Polytechnic University of Turin (2000). She is PhD in Drawing and Survey for the protection of building and land heritage (Polytechnic of Turin, 05 may 2005). She was the person in charge of the CNR project - Young Researchers (2004 edition) 3D measurement and modelling for Cultural Heritage protection. She took part in different operating units 
S. Armağan Güleç Korumaz \& Grazia Tucci \& Mustafa Korumaz \& Valentina Bonora

working for national and international research projects financed by MIUR and EU. She has taken part in many important archaeological and architectural surveys in Italy and abroad. She deals in particular with studying and testing innovative solutions for metric documentation and monitoring of Cultural and Land Heritage. 